\title{
Fatores de influência no preço do milho no Brasil
}

\author{
Palauras-chave \\ milho, soja, preço, séries \\ temporais.
}

Classificação JEL Q11, C32.

\section{Key words}

corn, soybean, price, time series.

JEL Classification Q11; C32

\section{Resumo}

Compreender a dinâmica de funcionamento do mercado de milho brasileiro, procedendo a uma investigação dos fatores que afetam as quantidades e preços nesse mercado, é o objetivo deste trabalho. Os testes de raiz unitária foram feitos utilizando-se a metodologia DF-GLS - Dickey Fuller Generalized Least Square - e os de cointegração de Johansen (1988). O modelo estimado, de ajuste pelo preço, foi um Modelo de Autorregressão Vetorial com Correçấo de Erros - VEC, sendo a identificaçáo feita pelo procedimento de Sims-Bernanke. O estudo permite afirmar que existe forte interação entre os mercados de milho e de soja, mostrando uma relação de complementaridade na oferta e substitutibilidade na demanda, e que fatores macroeconômicos como renda e juros sáo importantes na determinação dos preços do milho ao produtor e no atacado. Vale ressaltar que os preços externos do milho mostraram relativa importância no processo de formação do preço doméstico do grão.
Carlos Eduardo Caldarelli Professor adjunto da Universidade Estadual de Londrina - UEL

Mirian Rumenos Piedade Bacchi Professora associada do Departamento de Economia, Administraçắo e Sociologia da ESALQ/USP

\section{Abstract}

The objective of this paper is to understand the dynamics of the Brazilian corn market by investigating the main factors affecting volumes and prices. Unit roots tests were taken using the DF-GLS - Dickey Fuller Generalized Least Square methodology, and Johansen's cointegration tests (1988). The estimated model for price adjustment was a Self-Regression Vector Error Correction Model - VEC, with identification by the Sims-Bernanke procedure. We conclude that there is a significant interaction between the corn and the soybean markets, which present a complementary relationship on the supply side and substitution relationship on the demand side. Additionally, we conclude that macroeconomic factors such as income and interest rates are important in determining corn prices for producers and on the wholesale market. It should be noted that external grain prices play a relatively important role in formation of domestic corn prices. 


\section{1_Introdução}

Neste estudo, tem-se como objetivo central analisar os principais fatores que afetaram os preços e as quantidades comercializadas no mercado brasileiro de milho, no período de 1967 a 2008, procedendo à estimação de modelos econométricos. Além disso, deve possibilitar a análise dos principais determinantes de oferta e demanda no setor, destacando a importância da soja nesse contexto.

Embora tenham características distintas, os mercados de milho e soja apresentam fatores de interação, seja de substitutibilidade na oferta - competindo principalmente pelo fator terra -, seja de complementaridade na demanda - composição de raçôes.

A cadeia produtiva do milho é uma das mais importantes do agronegócio brasileiro, o qual, considerando apenas a produção primária, responde por $37 \%$ da produção nacional de grãos. A demanda crescente, tanto interna como externa, reforça o grande potencial do setor; junto com a soja, o milho é insumo básico para a avicultura e a suinocultura, dois mercados extremamente competitivos internacionalmente e geradores de receita para o Brasil. Ao mesmo tempo, constituem-se entraves da cadeia produtiva do milho a falta de clareza na formação dos preços, a dificul- dade de acesso a financiamentos privados, os problemas na comercialização e a baixa produtividade (Brasil, 2007). Levando-se em conta as oportunidades e os desafios do mercado brasileiro de milho, este trabalho tem como objetivo diagnosticar e analisar os fatores que determinam a oferta e a demanda nesse setor, destacando a importância da soja nesse contexto.

Buscou-se definir modelos teóricos que darão suporte à especificação dos econométricos, tendo em mente as características dos mercados analisados. Este estudo tem por hipótese que existe relação de complementaridade na demanda e relação de substitutibilidade entre a oferta desses bens. $\mathrm{O}$ modelo teórico proposto, de ajuste pelo preço, descreve de maneira estilizada o funcionamento do mercado de milho brasileiro. Uma identificação do tipo Sims-Bernanke fundamentou a definição de um modelo de Autorregressão Vetorial com Correção de Erro - VEC.

$\mathrm{O}$ artigo está dividido em seis partes, em que, depois da introdução (parte 1), tem-se um panorama da cadeia produtiva do milho; a parte 3 apresenta o modelo teórico, a parte 4 , a metodologia. Por fim, a parte 5 expóe os resultados e discussões, e a parte 6 finaliza o artigo com as principais conclusões. 


\section{2_Cadeia produtiva do milho no Brasil}

O milho é o principal macroingrediente para a produção de raçóes. Dada a importância na competitividade do mercado brasileiro de carnes, a produção do grão tem aumentado gradativamente (especialmente na segunda safra). Segundo dados da Conab (2009), de 1989/90 a 2008/09, o volume de milho produzido no Brasil (primeira e segunda safras) expandiu-se em 30,02 milhóes de toneladas.
A produção brasileira de milho tem apresentado tendência de elevação desde o fim da década de 80 (Figura 1). Fatores microeconômicos, como a maior rentabilidade - expressa por um aumento no preço recebido pelo produtor, associados a fatores macroeconômicos, como a desregulamentaçáo da economia (menor intervenção estatal) e a eliminação de tarifas sobre produtos importados (Tratado de Assunção), conduziram a produção nacional de grãos a uma realidade mais competitiva.

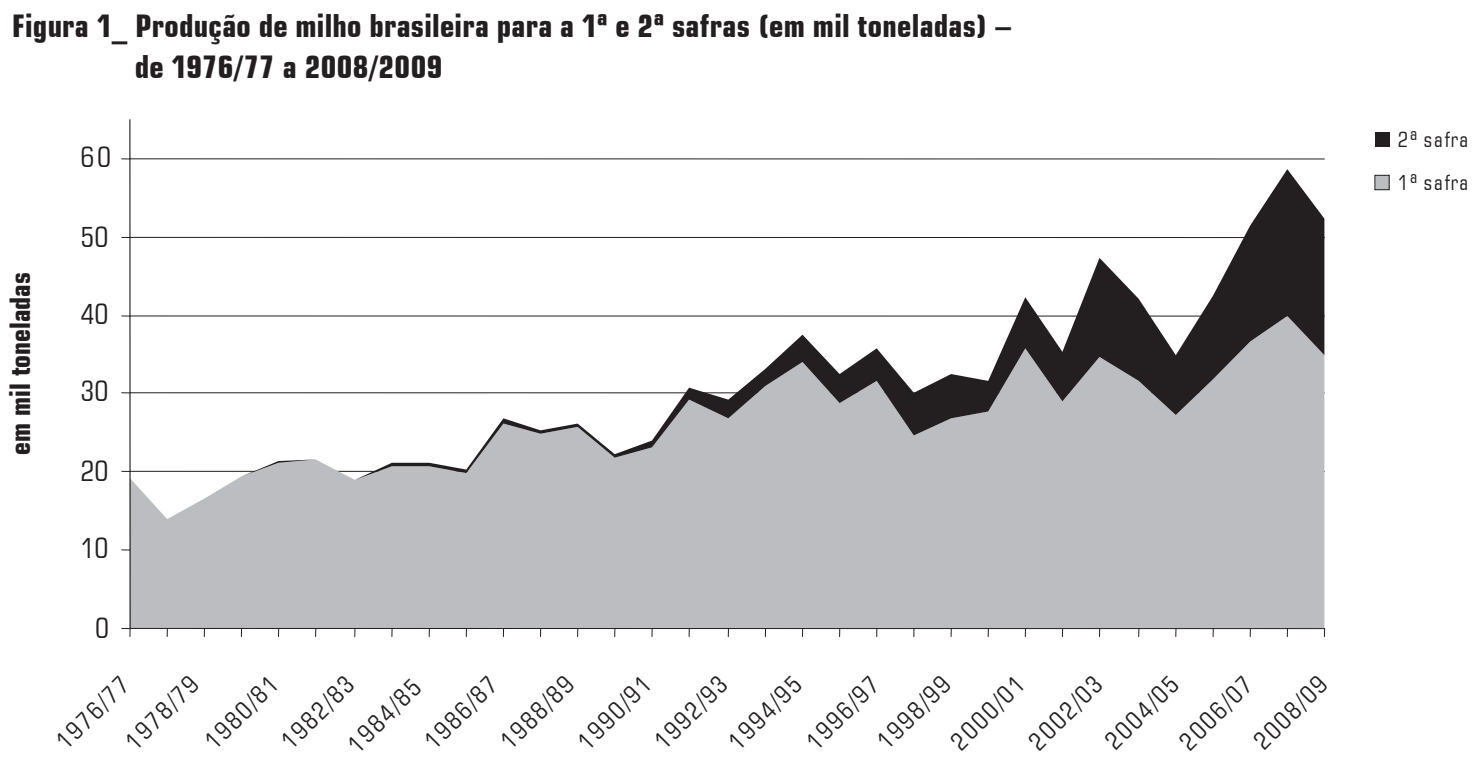


Expostos a maior competição com o milho importado, produtores brasileiros precisaram buscar aumentos contínuos de produtividade, o que ocasionou crescimento na produçáo nacional. O início da década de 90 foi um período caracterizado por importação maior de milho, principalmente dos países do Mercosul (Brasil, 2007). Entre outros fatores, os incentivos à soja, os efeitos de escala decorrentes da maior produção e a disseminação da cultura pelo Brasil são responsáveis pelo au- mento de produtividade do milho de segunda safra.

De acordo com dados da Conab (2009), a área plantada com milho safrinha expandiu 4,61 milhóes de hectares entre 1989/90 e 2008/09. As regióes Centro-Oeste e Sul foram as grandes responsáveis pelo expressivo aumento na área plantada com milho safrinha (Figura 2). Entre 1989/90 e 2008/09, o incremento foi de 2,81 milhôes de hectares no Centro-Oeste e de 1,41 milhôes de hectares no Sul.

Figura 2 - Área plantada do milho para a 2a safra por região (em mil hectares) de 1989/90 a 2008/09

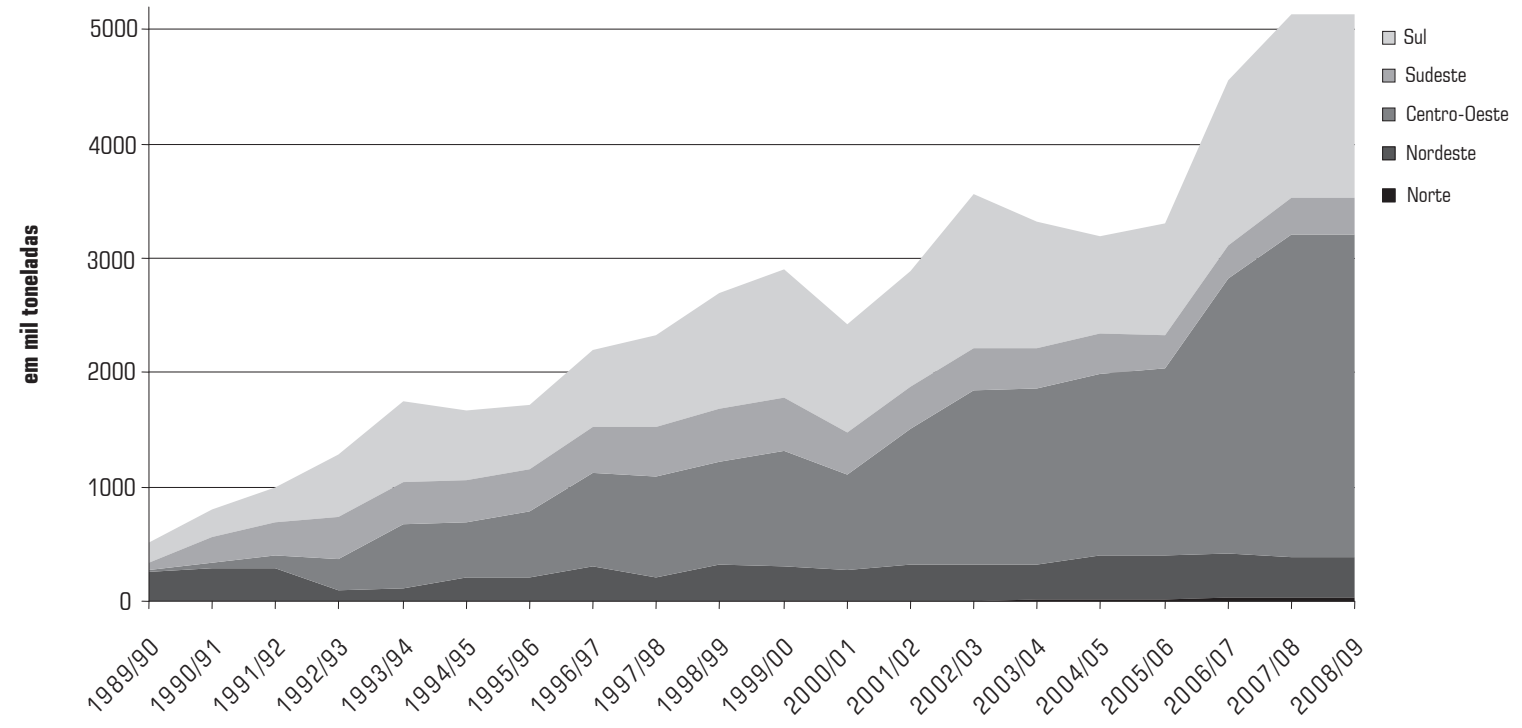

Fonte: Elaborado pelos autores com dados de Conab (2009). 
A produção brasileira de milho está concentrada nas Regióes Sul, Centro-Oeste e Sudeste. Os quatro maiores Estados produtores (Paraná, Mato Grosso, Rio Grande do Sul e Minas Gerais) são responsáveis por $51,04 \%$ da produção nacional (safra 2007/08).

Apesar dos aumentos contínuos na produtividade do grão, a cadeia brasileira de milho ainda tem baixa expressão no mercado externo; o Brasil não é um exportador tradicional do grão. Assim, a produção brasileira segue a tendência determinada pelas condiçóes do mercado doméstico, apresentando pouca interação com o mercado internacional. Da mesma maneira, a formação dos preços do milho no Brasil é grandemente influenciada por fatores do próprio mercado, sendo pouco afetada por movimentos no mercado mundial do grão (Chiodi, 2006).

A formação dos preços internos do milho é dependente de condicionantes regionais de oferta e demanda, que vêm registrando alteraçôes nos últimos anos com o crescimento significativo da produção de milho safrinha. Enquanto em 1989/90 a participação da segunda safra no total produzido foi de apenas $2 \%$, em $2008 / 09$ saltou para $33,32 \%$ (Brasil, 2007).
Como a comercialização constitui o processo de ligação entre a produção e o consumo, a análise do inter-relacionamento dos segmentos intermediários a esse processo se torna fundamental para o entendimento do mercado. Entre as características desse sistema a serem destacadas, estão sua abrangência, no que diz respeito a produtos finais, e sua interação com os demais sistemas agroindustriais como insumo. Se por um lado o milho é empregado como matéria-prima em diversos produtos finais, em mercados distintos, por outro a maior parte do milho toma a forma de insumo em diversos outros sistemas agroindustriais, principalmente voltados à produção animal (Souza; Azevedo; Saes, 1998).

A importância da cadeia do milho para outras atividades fica evidenciada quando se analisa o consumo por segmento. Os setores de aves e suínos foram responsáveis por $81,59 \%$ do consumo total do grão no Brasil, em 2007 (Tabela 1). $\mathrm{O}$ aumento do porte e da competitividade dessas atividades nos últimos anos tem feito com que o consumo de milho, principal insumo, apresente taxas elevadas de crescimento. Entre 2001 e 2007, a avicultura apresentou incremento de 89,29\% no consumo de milho e a suinocultura, de 40,13\% (Associação Brasileira das Indústrias do Milho - Abimilho, 2009). 
Tabela 1 _ Consumo de milho no Brasil por segmento (em tonelada) - de 2001 a 2007

\begin{tabular}{|c|c|c|c|c|c|c|c|}
\hline Segmento $\quad$ Ano & 2001 & 2002 & 2003 & 2004 & 2005 & 2006 & 2007 \\
\hline Avicultura & 13479 & 14500 & 15427 & 16162 & 19309 & 20022 & 20515 \\
\hline Suinocultura & 8579 & 8930 & 8471 & 8852 & 11236 & 11097 & 12022 \\
\hline Pecuária & 2722 & 2841 & 1911 & 2198 & 2420 & 2479 & 2374 \\
\hline Outros animais & 1528 & 1543 & 1550 & 1581 & 615 & 660 & 673 \\
\hline Consumo industrial & 4050 & 4090 & 4152 & 4256 & 4044 & 4159 & 4360 \\
\hline Consumo humano & 1505 & 1514 & 1530 & 1568 & 690 & 700 & 705 \\
\hline Perdas/sementes & 998 & 913 & 1660 & 1429 & 296 & 310 & 349 \\
\hline Exportação & 2550 & 1583 & 3988 & 5000 & 869 & 4327 & 5000 \\
\hline Outros & 3622 & 3550 & 4809 & 4132 & 100 & 0 & 9 \\
\hline Total & 39091 & 39464 & 43498 & 45178 & 39579 & 43754 & 46007 \\
\hline
\end{tabular}

Fonte: Abimilho (2009).

Segundo aponta a Abimilho (2009), a tendência de aumento no consumo de milho por parte da indústria de carnes deve ser mantida nos próximos anos. Tal fato se deve ao baixo uso de substitutos ao milho na alimentação animal (aves e suínos, principalmente) e às projeçôes de expansão dessas atividades.

\section{Modelo teórico}

No modelo proposto no presente estudo, de ajuste pelo preço, consideram-se dois níveis de mercado, o produtor e o atacado. Para a especificação desse, temse por base o desenvolvido por Barros
(1990) e parte-se de uma função de produção para o atacado do tipo Leontief (proporçóes fixas) descrita por :

$A=\min \left(\frac{P}{c_{1}}, \frac{X}{c_{2}}\right)$

onde $A$ representa a quantidade de milho no atacado; $P$, a quantidade de milho ao produtor; $X$, um insumo de comercialização usado ao atacado, e $c_{1}$ e $c_{2}$ representam os coeficientes técnicos.

Uma pressuposição do modelo é que os preços ao atacado ajustam-se instantaneamente em função do excesso de demanda, ou seja: 


$$
a_{t}-a_{t-1}=\delta\left(A_{t}^{d}-A_{t}^{S}\right) \quad \delta>0
$$

sendo $a_{t}$ os preços do milho ao atacado, e $A_{t}^{d}, A_{t}^{S}$, as quantidades de milho demandada e ofertada ao atacado, respectivamente.

Segundo Barros (1990), justifica-se o ajustamento instantâneo em nível de atacado por três fatores: i) o custo de mudança de preços é negligível; ii) as transações são bastante frequentes, existindo intensa comunicação entre compradores e vendedores; e iii) os produtos geralmente são perecíveis, sendo alto o custo de se deixar de efetuar uma transação.

Tal como descrito por Heien (1980), admite-se que a oferta ao atacado $\left(A_{t}^{s}\right)$ seja uma parcela $1 / d$ da oferta ao nível do produtor $\left(P_{t}^{s}\right)$ :

$A_{t}^{s}=\frac{1}{d_{1}} P_{t}^{S}$

e que a demanda de milho ao atacado seja dada por:

$$
A_{t}^{d}=\theta_{0}+\theta_{1} a_{t}+\theta_{2} Y_{t}+\theta_{3} p s_{t}
$$

sendo $Y$ a renda e $p s$ o preço da soja. ${ }^{1}$ Para a demanda ao atacado $\left(A_{t}^{d}\right)$, considera-se uma relaçáo baseada em uma função de produção neoclássica, incluindo o preço do milho ao atacado, a renda (representada pelo Produto Interno
Bruto real) e o preço do bem substituto/ complementar - a soja. Esperam-se os seguintes sinais para (4): $\theta_{1}<0, \theta_{2}>0$ e uma indeterminação quanto ao sinal de $\theta_{3}$ - de acordo com a relaçáo existente na demanda (positivo para substituto e negativo para complementar).

No caso da oferta de milho ao produtor (mercado interno), tal relação é representada por:

$$
\begin{aligned}
P_{t}^{S}= & \gamma_{0}+\gamma_{1} p_{t}+\gamma_{2} p s_{t}+\gamma_{3} i_{t}+ \\
& +\gamma_{4} p m e_{t}
\end{aligned}
$$

onde:

$\boldsymbol{p}$ é o preço de milho ao produtor; $p s$ é o preço da soja ao produtor; $i$ é a taxa de juros (usada como proxy para custos de produçáo/custo de armazenagem), e

pme é o preço do milho no mercado externo.

em que $\gamma_{1}>0, \gamma_{4}<0$, existindo indeterminação quanto ao sinal de $\gamma_{2}$ negativo para bens substitutos e positivo para bens complementares e em relação a $\gamma_{3}$ - conforme $i$ seja tomado como proxy para custos de produção ou para custos de armazenagem.

Segundo Barros (1990), nos segmentos varejo e produtor, admite-se que as transações se deem de forma descen- 
tralizada e com alguma defasagem em relação às transaçóes ao atacado. As mudanças de preço se processam por meio de ajustes parciais, e o preço de equilíbrio de mercado é alcançado somente após razoável permanência das alterações havidas nas condiçóes de oferta e demanda.

O "preço meta" ao produtor é estabelecido por meio de uma política de mark-up inverso, sendo os ajustes parciais em relação ao atacado, que é representado da seguinte forma:

$p_{t}^{*}=\frac{a_{t}-c_{2} x_{t}}{c_{1}}$

com $x_{t}$ representando o preço dos insumos de comercialização.

Assim, dado um "preço meta", o preço ao produtor ajusta seu preço de acordo com a expressão:

$p_{t}-p_{t-1}=\beta\left(p_{t}^{*}-p_{t-1}\right)$

sendo:

$0<\beta<1$

e:

$\beta>0$
Substituindo-se (6) em (7) tem-se:

$p_{t}-p_{t-1}=\beta\left(\frac{a_{t}-c_{2} x_{t}}{c_{1}}-p_{t-1}\right)$

$p_{t}=\frac{\beta}{c_{1}} a_{t}-\frac{\beta c_{2}}{c_{1}} x_{t}-\beta p_{t-1}+p_{t-1}$

$p_{t}=\frac{\beta}{c_{1}} a_{t}-\frac{\beta c_{2}}{c_{1}} x_{t}+(1-\beta) p_{t-1}$

A expressão (9) representa o processo de formação de preços no mercado de milho no nível do produtor. Espera-se:

$$
\frac{\beta}{c_{1}}>0, \frac{\beta c_{2}}{c_{1}}>0 \text {. }
$$

Como já mencionado, no modelo pressupóe-se que no atacado a oferta é formada com base na oferta do produtor, assim:

$$
A_{t}^{S}=\frac{1}{d_{1}} P_{t}^{S}
$$

ou:

$A_{t}^{S}=b_{1} P_{t}^{S}$

sendo:

$b_{1}>0$

\section{é dada por:}




$$
P_{t}^{S}=\gamma_{0}+\gamma_{1} p_{t}+\gamma_{2} p s_{t}+\gamma_{3} i_{t}+\gamma_{4} p m e_{t}
$$

Substituindo-se (66) na expressão que descreve a oferta ao atacado $\left(A_{t}^{s}\right)$, tem-se:

$$
A_{t}^{S}=b_{1}\left(\gamma_{0}+\gamma_{1} p_{t}+\gamma_{2} p s_{t}+\gamma_{3} i_{t}+\gamma_{4} p m e_{t}\right)
$$

ou:

$$
A_{t}^{S}=b_{1} \gamma_{0}+b_{1} \gamma_{1} p_{t}+b_{1} \gamma_{2} p s_{t}+b_{1} \gamma_{3} i_{t}+b_{1} \gamma_{4} p m e_{t}
$$

sendo: $b_{1} \gamma_{1}>0, b_{1} \gamma_{4}>0$ e $b_{1} \gamma_{2}, b_{1} \gamma_{3}$ indeterminados - dependendo das relaçôes de demanda entre os mercados de milho e soja (substitutos ou complementares) e de prevalecer em relação à taxa de juros, o efeito sobre custos de produção ou o sobre armazenagem.

A quantidade ofertada de milho no atacado $\left(A_{t}^{S}\right)$ é descrita, então, como uma função da oferta de milho ao produtor $\left(P_{t}^{S}\right)$ e relaciona-se funcionalmente com o preço pago aos produtores de milho, com o preço da soja, com a taxa de juros e com o preço do milho no mercado internacional. $\mathrm{Na}$ relação proposta, considera-se o modelo básico de oferta explicitado em Barros (1987), o modelo de oferta no atacado apresentado por Barros (1990), incorporando-se elementos referentes ao mercado externo.

Como no atacado os preços se ajustam em função do excesso de demanda, tem-se:

$$
a_{t}-a_{t-1}=\delta\left(A_{t}^{d}-A_{t}^{s}\right)
$$

Substituindo as expressóes que descrevem a oferta (10) e a demanda no atacado (4) na equação acima, resulta em:

$$
\begin{aligned}
a_{t}-a_{t-1}=\delta\left(\theta_{0}+\theta_{1} a_{t}+\theta_{2} Y_{t}+\right. & \\
& +\theta_{3} p s_{t}-b_{1} \gamma_{0}-b_{1} \gamma_{1} p_{t}-(11) \\
& \left.\quad-b_{1} \gamma_{2} p s_{t}-b_{1} \gamma_{3} i_{t}-b_{1} \gamma_{4} p m e_{t}\right) \\
a_{t}= & \frac{\delta\left(\theta_{0}-b_{1} \gamma_{0}\right)}{1-\delta \theta_{1}}+\frac{\delta \theta_{2}}{1-\delta \theta_{1}} Y_{t}+ \\
+ & \frac{\delta \theta_{3}}{1-\delta \theta_{1}} p s_{t}-\frac{\delta b_{1} \gamma_{1}}{1-\delta \theta_{1}} p_{t}- \\
- & \frac{\delta b_{1} \gamma_{2}}{1-\delta \theta_{1}} p s_{t}-\frac{\delta b_{1} \gamma_{3}}{1-\delta \theta_{1}} i_{t}- \\
- & \frac{\delta b_{1} \gamma_{4}}{1-\delta \theta_{1}} p m e_{t}+\frac{a_{t-1}}{1-\delta \theta_{1}} \\
a_{t}= & \frac{\delta\left(\theta_{0}-b_{1} \gamma_{0}\right)}{1-\delta \theta_{1}}+\frac{\delta \theta_{2}}{1-\delta \theta_{1}} Y_{t}+ \\
+ & \frac{\delta\left(\theta_{3}-b_{1} \gamma_{2}\right)}{1-\delta \theta_{1}} p s_{t}-\frac{\delta b_{1} \gamma_{1}}{1-\delta \theta_{1}} p_{t}- \\
& -\frac{\delta b_{1} \gamma_{3}}{1-\delta \theta_{1}} i_{t}-\frac{\delta b_{1} \gamma_{4}}{1-\delta \theta_{1}} p m e_{t}+\frac{a_{t-1}}{1-\delta \theta_{1}}
\end{aligned}
$$


Renomeando-se os parâmetros, tem-se, simplificadamente:

$$
\begin{aligned}
a_{t} & =c_{0}+c_{1} Y_{t}+c_{2} p s_{t}- \\
& -c_{3} p_{t}-c_{4} i_{t}-c_{5} p m e_{t}
\end{aligned}
$$

A expressão (13) descreve a formação de preços no mercado de milho ao nível do atacado. Dessa relação, espera-se que: $c_{1}>0, c_{3}>0, c_{5}<0$, sendo o sinal de $c_{2}$ e $c_{4}$ indeterminado. Se $\theta_{3}$ for negativo, considerando que a soja e o milho sejam produtos complementares na função de demanda, e $\gamma_{2}$ for negativo, considerando que o milho e a soja sejam produtos substitutos na função de oferta, o sinal de $c_{2}$ vai depender das magnitudes de $\theta_{3}$ e $\gamma_{2}$ em valores absolutos. Se o valor de $\gamma_{2}$ for maior do que o de $\theta_{3}$, então o sinal de $c_{2}$ vai ser positivo. Se o efeito da taxa de juros for maior no processo de formação de estoque do que na determinação de custos de produção, o sinal de $c_{4}$ será negativo e vice-versa.

A matriz de relaçôes contemporâneas representando o modelo econômico é expressa na Tabela 2.

\section{4_Metodologia}

O teste DF-GLS, apresentado em Elliot, Rothenberg e Stock (1996), foi utilizado para verificar a existência de raiz unitária nas séries. Essa metodologia, versão eficiente do teste Dickey-Fuller Aumentado - ADF, consiste na aplicação do teste ADF à série previamente filtrada de seus componentes determinísticos. $\mathrm{O}$ número de defasagens utilizadas no

Tabela 2 _ Matriz de relações contemporâneas entre as variáveis para o modelo do mercado de milho

\begin{tabular}{l|l|l|l|l|l|l|l|l} 
& $\mathbf{A}$ & $\mathbf{a}$ & $\mathbf{p}$ & $\mathbf{p s}$ & $\mathbf{Y}$ & $\mathbf{i}$ & $\mathbf{p m e}$ \\
\hline $\mathrm{A}$ & $\mathbf{1}$ & 1 & 0 & 1 & 1 & 0 & 0 \\
\hline $\mathrm{a}$ & 0 & $\mathbf{1}$ & 1 & 1 & 1 & 1 & 1 \\
\hline $\mathrm{p}$ & 0 & 1 & $\mathbf{1}$ & 0 & 0 & 0 & 0 \\
\hline $\mathrm{ps}$ & 0 & 0 & 0 & $\mathbf{1}$ & 0 & 0 & 0 \\
\hline $\mathrm{Y}$ & 0 & 0 & 0 & 0 & $\mathbf{1}$ & 0 & 0 \\
\hline $\mathrm{i}$ & 0 & 0 & 0 & 0 & 0 & $\mathbf{1}$ & 0 \\
\hline $\mathrm{p}$ & 0 & 0 & 0 & 0 & 0 & 0 & 1 \\
\hline
\end{tabular}

Fonte: Elaborado pelos autores com dados da pesquisa. 
teste de raiz unitária foi determinado através do Critério de Informação de Akaike Modificado - MAIC.

A metodologia para o teste de cointegração foi a proposta por Johansen (1988), que contempla tanto a existência de mais de um vetor de cointegração quanto a endogeneidade dos regressores. Esse teste equivale à estimativa de um sistema que contém exatamente $h$ relaçôes de cointegração através do método de Máxima Verossimilhança de Informação Plena - MVIP.

O modelo teórico apresentado na seção anterior foi estimado mediante a metodologia de Autorregressão Vetorial com Correção de Erro - Modelo VEC. Trata-se da aplicação da metodologia de Autorregressão Vetorial - VAR, quando as séries são integradas e cointegradas, assim, o modelo deve ser ajustado com as séries nas diferenças e deve-se incluir o termo de correção de erro. Optou-se pela utilização da decomposição do tipo Sims-Bernanke (do tipo VAR estrutural), na qual o modelo teórico é usado para estabelecer as relaçóes existentes (Enders, 2004).

\section{1_ Fonte dos dados}

Para os preços de soja e milho pagos aos produtores, assim como para os preços de milho ao atacado e no mercado externo, foram empregadas as séries divulgadas pelo Instituto de Pesquisa Econômica Aplicada - IPEA. O preço externo do milho foi transformado em real pela taxa de câmbio PTAX-800 (venda) divulgada pelo Banco Central do Brasil - Bacen. Como uma proxy dos custos de armazenagem, foi utilizada a taxa de juros Overnight/Selic, também divulgada pelo Bacen.

A série de quantidade demandada de milho ao atacado, respaldada nas pressuposiçôes do modelo, foi construída com base nos dados de produção nacional, divulgada pela Companhia $\mathrm{Na}$ cional de Abastecimento - Conab, e de importação e exportação nacional de milho, coletada no Sistema ALICE da Secretária de Comércio Exterior do $\mathrm{Mi}$ nistério do Desenvolvimento Indústria e Comércio Exterior.

A renda foi representada pelo Produto Interno Bruto - PIB, com base nos dados do Instituto Brasileiro de Geografia e Estatística - IBGE.

Os preços e valores, expressos em termos nominais, foram transformados em valores reais utilizando o IGP-DI - divulgado pela Fundação Getúlio Vargas.

Todas as séries foram transformadas em logaritmo para o ajustamento do modelo, de maneira que as relaçóes entre as variáveis possam ser tomadas como 
elasticidades. A análise, feita com dados anuais, abrange o período de 1967 a 2008.

\section{5_Resultados e discussão}

Os resultados dos testes de raiz unitária de Elliot, Rothenberg e Stock (1996), ou Dickey-Fuller Generalized Least Square - DF-GLS, apresentados na Tabela 3, levam a concluir que as séries quantidade de milho no atacado, preço de milho no atacado, preço de milho ao produtor, preço do milho no mercado externo, preço de soja ao produtor, taxa de juros e renda são integradas de ordem um - I(1). Não se pode rejeitar a hipótese nula de que há uma raiz unitária nessas séries, considerando o nível de significância de 10\% de probabilidade.

Foram utilizadas duas versôes do modelo: com constante e tendência e somente com constante (Tabela 3), e ambos os modelos apontam que todas as sé-

Tabela 3 _ Resultados dos testes de raiz unitária de Elliot-Rothenberg-Stock DF-GLS - para as séries (em nível) utilizadas no modelo

\begin{tabular}{l|c|c|c|c}
\multicolumn{1}{c|}{ Variável } & & Modelo 1 & & Modelo 2 \\
\cline { 3 - 5 } & $\mathbf{p}$ & Estatística DF-GLS & $\mathbf{p}$ & Estatística DF-GLS \\
\hline Quantidade de milho no atacado & 5 & $-0,7059^{*}$ & 0 & $0,2426^{*}$ \\
\hline Preço de milho no atacado & 2 & $-1,693^{*}$ & 5 & $-0,8243^{*}$ \\
\hline Preço do milho ao produtor & 2 & $-1,6097^{*}$ & 5 & $-1,0203^{*}$ \\
\hline Preço externo do milho & 3 & $-1,2123^{*}$ & 3 & $-0,5533^{*}$ \\
\hline Preço ao produtor de soja & 3 & $-1,7661^{*}$ & 3 & $-0,3448^{*}$ \\
\hline Taxa de juro & 2 & $-1,3807^{*}$ & 2 & $-1,3699^{*}$ \\
\hline Produto Interno Bruto & 3 & $-0,4125^{*}$ & 3 & $1,3176^{*}$ \\
\hline
\end{tabular}

Fonte: Elaborado pelos autores com dados da pesquisa.

Notas: Modelo $1 \Delta y_{t}^{\mu}=\beta_{0}+\beta_{1} t+\alpha_{0} y_{t-1}^{\mu}+\sum_{j=1}^{p} \alpha_{j} \Delta y_{t-j}^{\mu}+\varepsilon$, na versão com constante e tendência.

$$
\text { Modelo } 2 \Delta y_{t}^{\mu}=\beta_{0}+\alpha_{0} y_{t-1}^{\mu}+\sum_{j=1}^{p} \alpha_{j} \Delta y_{t-j}^{\mu}+\varepsilon \text {, na versấo somente com constante. }
$$

*Náo significativo ao nível de 0,10 de probabilidade - valores críticos em (Elliot; Rothenberg; Stock, 1996). 
ries são integradas de ordem um - I(1). Para a realização dos testes, foi usado o critério modificado de Akaike - MAIC para a determinação do número de defasagens a ser empregadas (p).

Para estimar e testar relaçóes de longo prazo estacionárias entre variáveis, ou análise de cointegração, usa-se o procedimento de Johansen (1988). Lançouse mão de tal procedimento por causa do contexto multivariado da análise e da possibilidade de se verificar mais de um vetor de cointegração.
O resultado do teste de cointegração de Johansen, usando-se a estatística traço, indica que existem três vetores de cointegração, a um nível de significância de 5\% de probabilidade (Tabela 4). Dessa forma, as relaçóes existentes entre os mercados de milho e soja brasileiros são estabelecidas utilizando-se o Modelo de Autorregressão Vetorial com Correção de Erros - VEC.

$\mathrm{Na}$ sequência, são apresentados os parâmetros estimados das funçóes de demanda de milho no atacado, de preço

Tabela 4 _ Resultados do teste de cointegração de Johansen

\begin{tabular}{|c|c|c|c|}
\hline $\begin{array}{l}\text { Hipótese Nula } \\
\qquad H_{0}\end{array}$ & $\begin{array}{l}\text { Hipótese Alternativa } \\
\qquad H_{A}\end{array}$ & $\begin{array}{c}\text { Estatística } \\
\text { Traço }\end{array}$ & $\begin{array}{c}\text { Valores críticos } \\
5 \%\end{array}$ \\
\hline $\mathrm{r} \leq 7$ & $r=7$ & 3,93 & 9,14 \\
\hline$. r \leq 6$ & $r=6$ & 10,39 & 20,16 \\
\hline$. r \leq 5$ & $r=5$ & 25,22 & 35,07 \\
\hline$. r \leq 3$ & $r=4$ & 54,02 & 56,94 \\
\hline$. r \leq 2$ & $\mathrm{r}=3$ & $86,63^{*}$ & 76,81 \\
\hline$. r \leq 1$ & $r=2$ & $131,23^{*}$ & 103,67 \\
\hline$r=0$ & $r=1$ & $181,06^{*}$ & 134,54 \\
\hline
\end{tabular}

Fonte: Elaborado pelos autores com dados da pesquisa.

Nota: O modelo foi ajustado com uma constante fora do espaço de cointegraçáo e uma defasagem. A significância da constante no vetor de cointegraçáo foi testada (distribuiçáo $\chi^{2}$ ) e não se rejeitou a hipótese de ela ser nula. Testou-se também a inclusáo de uma tendência no vetor de cointegraçăo, e a hipótese nula de que o coeficiente dessa variável seja igual a zero năo foi rejeitada.

* Significativo ao nível de 0,05 de probabilidade. 
Quadro 1 _ Estimativa das funções de demanda de milho no atacado, preço de milho no atacado e preço de milho ao produtor

Demanda de milho no atacado

$$
\underset{p-\text { valor }}{A_{t}^{d}}=\theta_{0} \underset{(0,41)}{0,15 a_{t}}+\underset{(0,94)}{0,011} p s_{t}+\underset{(0,63)}{0,14} Y_{t}+\varepsilon_{1}
$$

Preço de milho no atacado

$$
\underset{p-\text { valor }}{a_{t}}=c_{0}-\underset{(0,59)}{0,71 p_{t}}+\underset{(0,16)}{0,84} p s_{t}-\underset{(0,31)}{0,91 Y_{t}}-\underset{(0,29)}{0,29} i_{t}+\underset{(0,27)}{0,22} p m e_{t}+\varepsilon_{2}
$$

Preço de milho ao produtor

$$
\underset{p-\text { valor }}{p_{t}}=\underset{(0,00)}{0,87} a_{t}+\varepsilon_{3}
$$

Fonte: Dados da pesquisa.

de milho no atacado e de preço de milho ao produtor (Quadro 1).

Como as séries foram transformadas em primeiras diferenças dos logaritmos para a estimação do modelo, os resultados da matriz de relaçóes contemporâneas referem-se a elasticidades.

As estimativas dos parâmetros das relaçóes contemporâneas não se apresentaram estatisticamente significativos na maioria das equaçóes; entretanto, os sinais dos coeficientes estão de acordo com o esperado. A exceção em termos de compatibilidade entre o sinal esperado e estimado ficou por conta da renda - o que pode ter ocorrido pelo fato de o PIB não ser uma proxy adequada para representar o poder aquisitivo da população. ${ }^{2}$
Na equação do preço do milho ao produtor, o preço ao atacado apresentou um efeito de grande magnitude e significativo - elasticidade de transmissão de 0,87 , corroborando a pressuposição do modelo proposto de que a formação de preços no segmento produtor é grandemente dependente dos preços ao atacado.

A metodologia de Autorregressão Vetorial permite, além da estimativa dos parâmetros da matriz de relaçóes contemporâneas, a obtenção das funçôes de respostas a impulso. Tais funções possibilitam a análise da evolução das variáveis do sistema diante de choques não antecipados.

As Figuras 3 a 7 apresentam, para as principais variáveis do modelo, as
2 Ao longo da pesquisa, foi ajustado um modelo utilizando salário real como proxy para a renda; todavia, o modelo não apresentou convergência. 


\section{Figura 3 _ Respostas acumuladas das variáveis do modelo a um choque não antecipado no consumo aparente de milho}

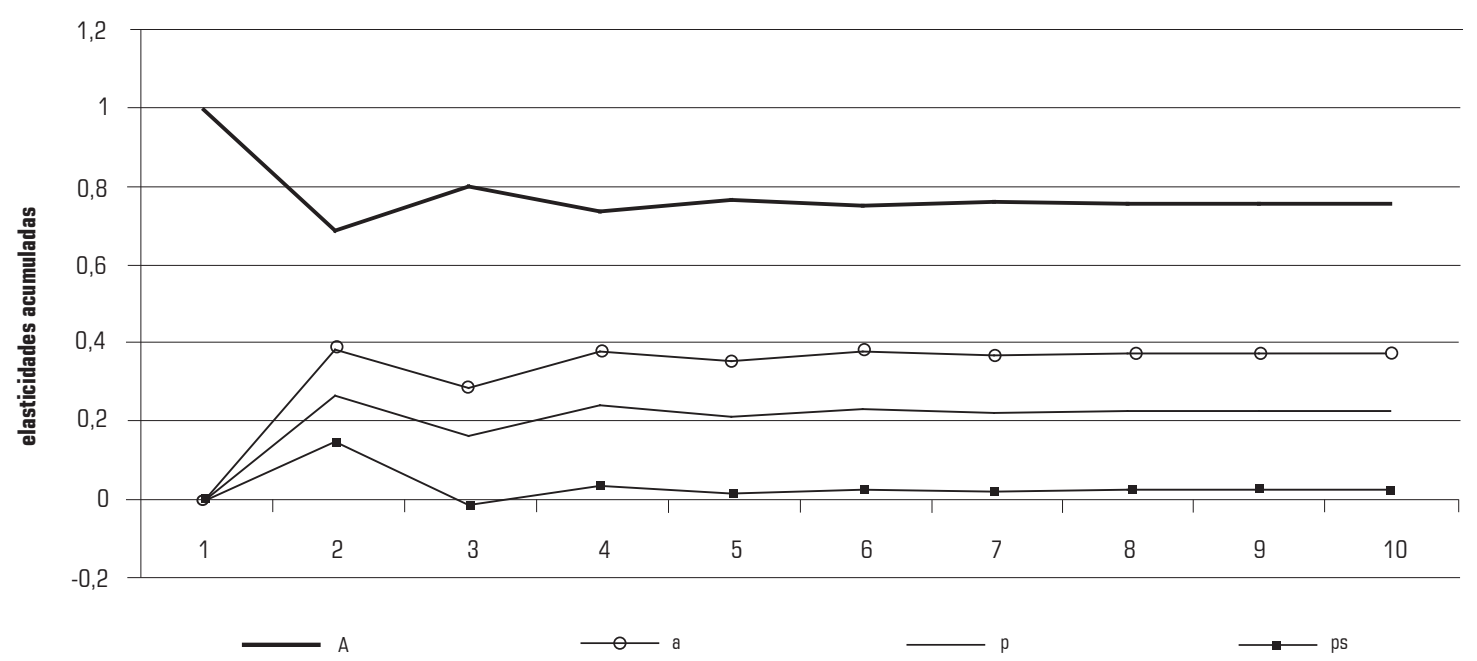

Fonte: Resultados obtidos pelos autores.

funçóes de respostas a impulso acumuladas no tempo. Na Figura 3, que mostra as respostas acumuladas de um choque não antecipado no consumo aparente de milho, observa-se que a variável que mais responde a esse choque é o preço desse cereal no segmento atacadista, seguido pelo preço do milho ao produtor e depois pelo preço da soja. No que diz respeito ao preço da soja, o efeito de um choque não antecipado no consumo aparente de milho é pequeno; no entanto, o sinal positivo indica complementaridade do milho e da soja em relação à demanda.
A Figura 4, na sequência, mostra os efeitos de um choque não antecipado no preço do milho ao atacado sobre as principais variáveis do sistema. Pode-se ver que o efeito do choque sobre o preço de milho ao produtor é expressivo. Esse resultado, assim como o obtido na matriz de relaçóes contemporâneas, é coerente com a pressuposição do modelo de que o preço do milho ao produtor é determinado pelo preço do grão no atacado. $\mathrm{O}$ efeito acumulado de um choque no preço do milho ao atacado sobre o consumo aparente é negativo e pequeno - próximo a -0,10, podendo-se concluir 


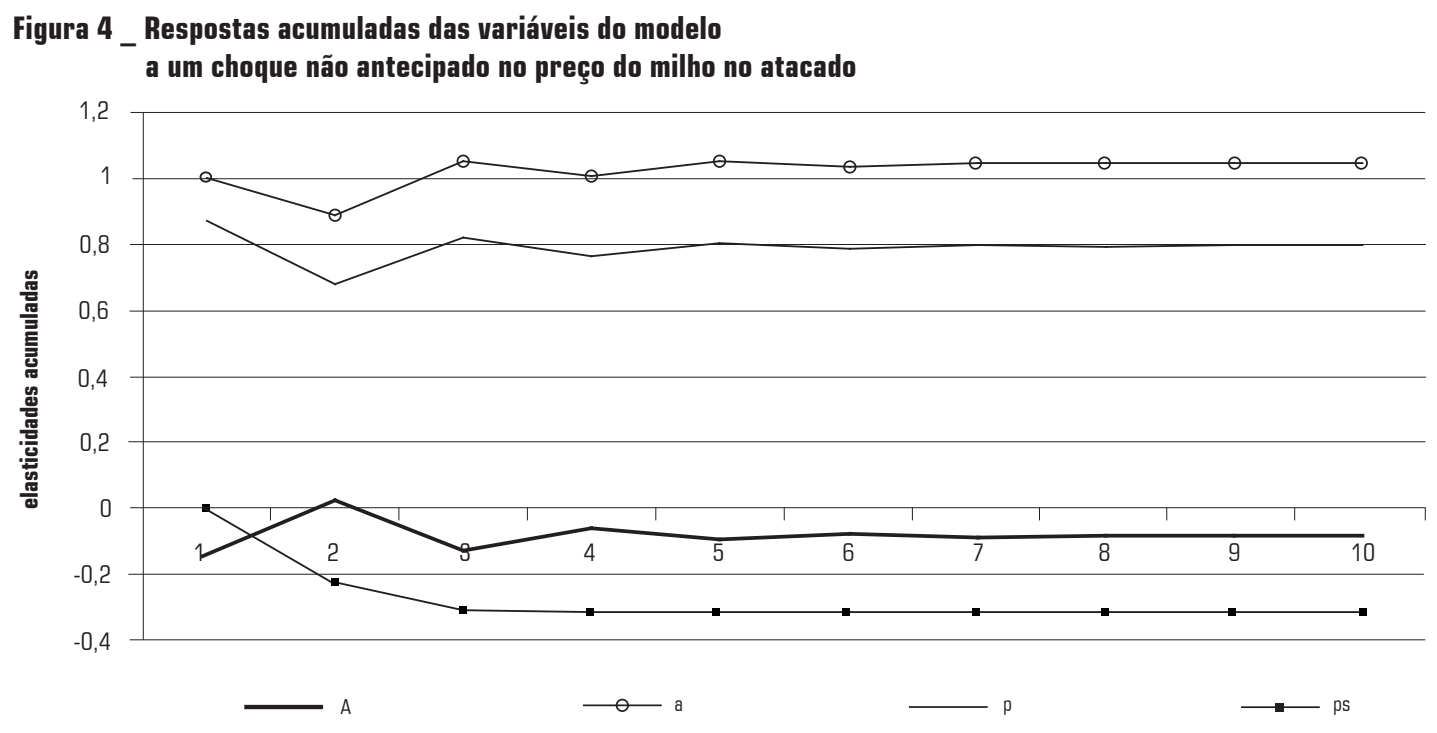

Fonte: Resultados obtidos pelos autores.

que a demanda é inelástica em relação ao próprio preço. Devido ao processo de identificação da matriz de relaçóes contemporâneas, tem-se valor nulo no primeiro período para a resposta do preço da soja ante um aumento percentual do preço do milho ao atacado. Embora as elasticidades negativas subsequentes possam estar associadas a uma queda no consumo aparente de milho, considerase o movimento bastante acentuado.

$\mathrm{Na}$ Figura 5, são apresentadas as repostas das principais variáveis do modelo perante um choque exógeno não antecipado no preço do milho ao produtor. Uma elevação do preço ao produtor leva a um aumento da rentabilidade e, consequentemente, da oferta. No período seguinte ao do choque, tanto o preço de milho ao produtor quanto o preço ao atacado caem de forma acentuada. Esse fenômeno de ciclos anuais de preços é observado com frequência nas atividades agrícolas, especialmente naquelas voltadas ao mercado interno. Verificamse, após o primeiro período, movimentos semelhantes (de queda) do preço do milho ao atacado e ao produtor, e movimentos contrários do consumo aparente de milho e do preço da soja (que, no primeiro período, não se deslocou dada a restrição imposta na matriz de re- 
Figura 5 _ Respostas acumuladas das variáveis do modelo

a um choque não antecipado no preço do milho ao produtor

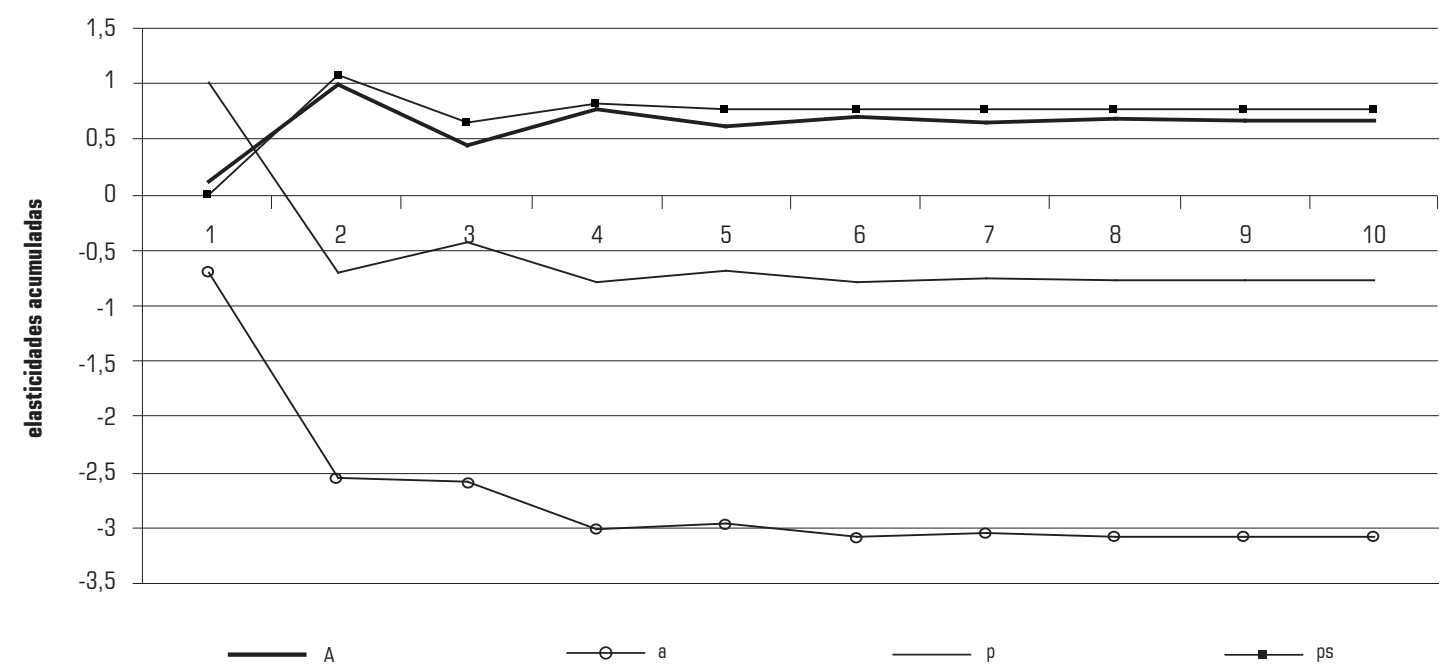

Fonte: Resultados obtidos pelos autores.

laçôes contemporâneas). O preço da soja aumenta no período seguinte ao que ocorreu o choque no preço do milho e se estabiliza no quarto ano, sendo a elasticidade acumulada de 0,7. Essa elevação do preço da soja está relacionada tanto ao fato de a soja ser um produto substituto do milho no segmento produtor quanto de ser complementar no atacado.

$\mathrm{Na}$ Figura 6, apresentam-se as respostas acumuladas das principais variáveis do modelo diante de um choque não antecipado no preço de soja no segmento produtor. No que concerne ao mercado de milho, tal choque mostra efeitos consideráveis e positivos tanto no segmento produtor quanto no atacadista. Como o consumo aparente de milho sofre apenas pequeno impacto do aumento do preço da soja (havendo baixa elasticidade-preço cruzada da demanda), os aumentos observados nos preços de milho são decorrentes, principalmente, da substitutibilidade desses produtos no sistema produtivo.

Por fim, a Figura 7 apresenta os resultados de um choque náo antecipado no preço do milho no mercado internacional. A análise dessa função de respostas a impulso permite que se conclua que os efeitos de um choque no preço do milho no mercado externo são positivos so- 


\section{Figura 6 _ Respostas acumuladas das variáveis do modelo}

a um choque não antecipado no preço da soja

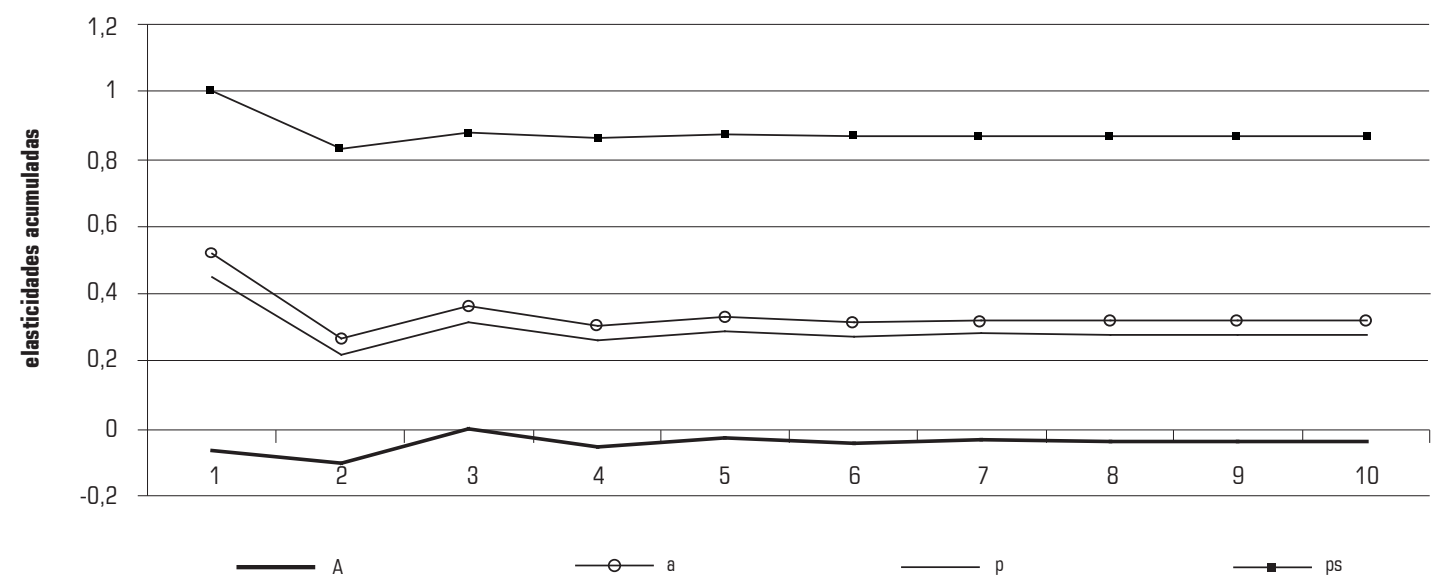

Fonte: Resultados obtidos pelos autores.

bre os preços do cereal no mercado doméstico, sendo o de maior magnitude o que ocorre sobre o preço do milho ao atacado. Então, a possibilidade de arbitragem deve ser considerada no processo de formação de preço de milho no mercado doméstico. Verifica-se que um choque no preço do milho no mercado internacional pouco afeta o consumo aparente desse cereal no mercado brasileiro. Assim, o preço do mercado externo é referência para o do mercado doméstico, mas o efeito daquela variável sobre o consumo aparente não é significativo, o que pode estar ocorrendo pelo fato de as exportaçôes brasileiras não terem ainda grande representatividade e também pelo fato de a elasticidade-preço do consumo de milho ser pequena, como já mencionado.

A análise das funções de respostas a impulso permite que se conclua que os efeitos dos choques não antecipados sobre as variáveis do sistema são de curta duração, desaparecendo, na maior parte das vezes, após o terceiro ano.

$\mathrm{Na}$ Tabela 5, são apresentados os valores acumulados das elasticidades ${ }^{3}$ estimadas por meio das funçóes de respostas a impulso nos quatro primeiros anos após um choque não antecipado, em cada variável do sistema. As variáveis que recebem o choque estão representadas nas linhas, e os seus efeitos, nas colunas correspondentes.

\footnotetext{
${ }^{3}$ As funçóes de respostas a impulso não são originalmente obtidas em elasticidades, mas, como na estimação do modelo utilizam-se variáveis em logaritmo, a divisão dos valores pelo da variável que recebeu o choque permite a obtenção das elasticidades (Bacchi, 2007).
} 
Figura 7 Respostas acumuladas das variáveis do modelo

a um choque não antecipado no preço externo do milho

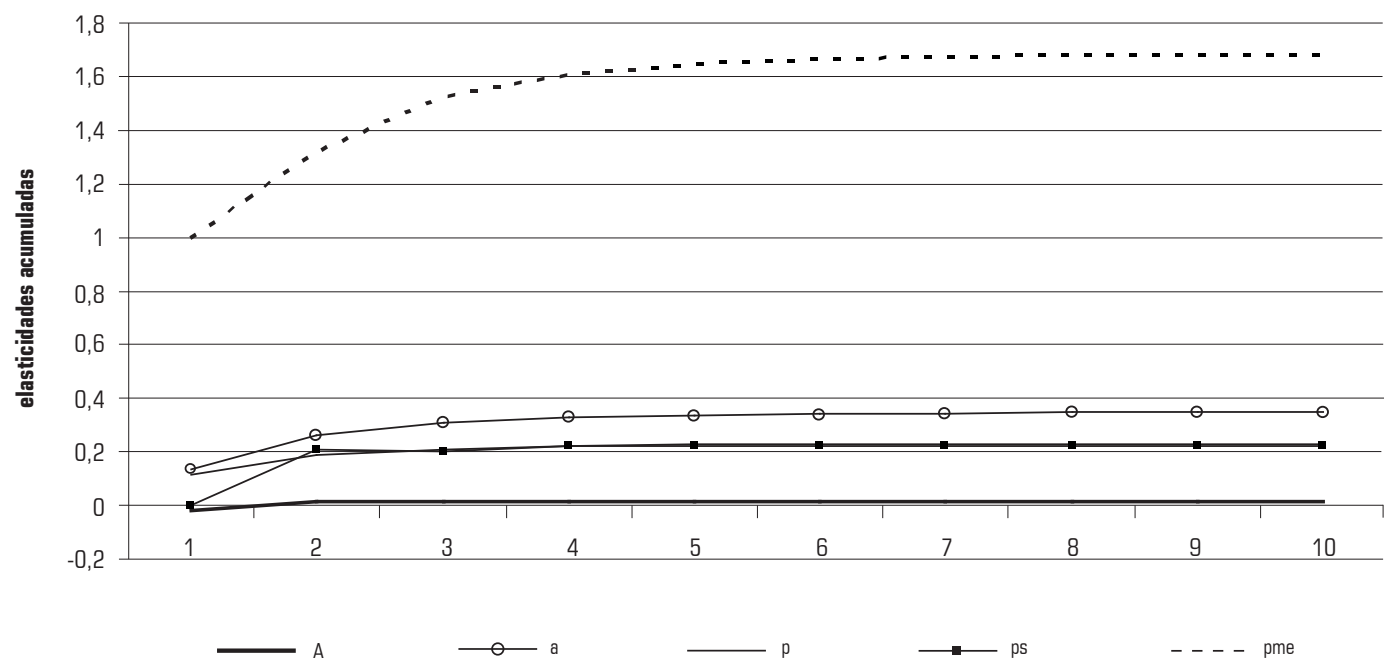

Fonte: Resultados obtidos pelos autores.

Tabela 5 _ Efeitos das elasticidades acumuladas nos quatro primeiros anos após um choque em cada variável do modelo

\begin{tabular}{|c|c|c|c|c|}
\hline Choque & A & a & $\mathbf{p}$ & ps \\
\hline A & 0,737884 & 0,384257 & 0,243319 & 0,040835 \\
\hline $\mathrm{a}$ & $-0,05979$ & 1,005543 & 0,763215 & $-0,31357$ \\
\hline $\mathrm{p}$ & 0,766965 & $-3,01217$ & $-0,79012$ & 0,813115 \\
\hline ps & $-0,0568$ & 0,304007 & 0,261093 & 0,86443 \\
\hline Y & 0,337631 & 0,139537 & 0,146533 & 0,970659 \\
\hline $\mathrm{i}$ & 0,052776 & $-0,22739$ & $-0,16221$ & 0,072395 \\
\hline pme & 0,016424 & 0,32862 & 0,22109 & 0,220014 \\
\hline
\end{tabular}

Fonte: Resultados obtidos pelos autores. 
A análise das elasticidades acumuladas mostra que os efeitos de um choque não antecipado no consumo aparente de milho não são de grande magnitude, tanto no caso do preço de milho ao produtor $(0,24)$ quanto no caso do preço de milho ao atacado $(0,38)$. Não se observa efeito significativo sobre o preço da soja.

Um aumento não esperado de $1 \%$ no preço ao atacado tem efeito expressivo sobre o preço ao produtor $(0,76)$. Um choque não antecipado no preço ao atacado afeta de forma moderada o consumo aparente de milho, observando-se baixa elasticidade-preço da demanda nesse segmento $(-0,06)$. Nota-se elasticidade de transmissão de preço do milho ao atacado para o preço de soja moderada $(-0,31)$. As elasticidades relacionando um choque no preço da soja sobre os preços do milho ao atacado e ao produtor são da ordem de 0,30 e 0,26, respectivamente.

Um aumento no preço da soja não é sucedido por uma queda expressiva no ano seguinte, o que faz com que o consumo aparente de milho, como bem complementar da soja, sofra redução, o que compensa, em parte, o efeito de elevação do preço do milho. No caso de um aumento do preço do milho, a queda observada nesse preço no ano seguinte ao do choque faz com que o consumo aparente de milho aumente, acentuando o impacto sobre o preço da soja - somamse aqui os efeitos de substitutibilidade na produção e de complementaridade na demanda.

A renda afeta positivamente tanto o consumo aparente de milho quanto os preços de milho e soja. Um choque não antecipado sobre a renda aumenta o consumo aparente de milho, elevando os preços ao atacado e ao produtor desse grão. $\mathrm{O}$ preço da soja, considerando a relação de complementaridade na demanda, também aumenta.

Concernente ao preço do milho no mercado internacional, choques não antecipados nessa variável atingem todos os preços domésticos positivamente - preço do milho ao produtor, ao atacado e o preço de soja. Como o consumo aparente de milho não é afetado de forma significativa, conclui-se que o preço externo é tomado com referência para o interno, apesar de o processo de arbitragem não ocorrer de forma intensa. A simples possibilidade de existir arbitragem parece ser suficiente para que a influência do preço internacional de milho sobre o doméstico ocorra.

A taxa de juros tem efeito negativo sobre os preços de milho, prevalecendo sua influência sobre a formação 


\footnotetext{
${ }^{4}$ Modelos testados incluindo variáveis construídas para representar o consumo de milho desses animais, com base em dados de abate de frango e suíno defasados (considerando aspectos do ciclo produtivo de aves e suínos), não apresentaram bons ajustamentos, reduzindo o número de graus de liberdade.
}

de estoques relativamente ao aumento de custos. Assim, quando a taxa de juros aumenta, os preços caem em função do aumento de oferta, resultando em aumento do consumo aparente. É importante mencionar, no entanto, que as elasticidades são de pequena magnitude.

Os resultados da decomposição da variância dos erros de previsão, como esperado, são compatíveis com a forma como se procedeu a identificação da matriz de relaçóes contemporâneas.

Cumpre chamar a atenção para o fato de não se ter incluído no modelo variáveis que tratem do mercado de aves e suínos de forma direta, que, como já mencionado, são os principais setores do agronegócio brasileiro que utilizam o milho como insumo. Considera-se que essa limitação possa ser sanada no futuro, quando se dispuser de séries históricas mais longas e se possa trabalhar com maior número de graus de liberdade. ${ }^{4}$ No entanto, embora a ausência dessas variáveis possa constituir-se em um problema de especificação do modelo, acredita-se que o viés seja pequeno, uma vez que, quando se trabalha com modelos de séries temporais, como o VAR, a maior parte do efeito de variáveis explicativas omitidas é captada pelos termos autorregressivos.
Esse argumento encontra-se bem fundamentado na discussão apresentada em Vandaele (1983) dos modelos de função de transferência de Box e Jenkins, os quais contemplam apenas a influência de uma ou de poucas variáveis explicativas, considerando que a de todas as outras esteja refletida no passado histórico da série. Daí se considerar a influência da variável dependente defasada no modelo (através de termos autorregressivos e/ou de média móveis).

\section{6_Conclusões}

O objetivo principal do estudo foi investigar os fatores que afetam as quantidades comercializadas e os preços do milho no mercado brasileiro. O modelo teórico utilizado para fundamentar a especificação do modelo estatístico baseouse nos desenvolvidos por Heien (1980) e por Barros (1990). Considerou-se que o preço no atacado se forma por excesso de demanda e no segmento produtor por mark-up inverso. Além de variáveis do próprio mercado de milho e do mercado de soja, que são segmentos do agronegócio brasileiro reconhecidamente bastante relacionados, variáveis macroeconômicas como juro e renda foram inseridas no modelo como deslocadoras da oferta e de demanda de milho, respectivamente. 
Os resultados que tratam das relações contemporâneas entre as variáveis mostram que há interação entre os mercados de soja e de milho e que a elasticidade de transmissão do preço de milho do segmento atacadista para o segmento produtor é elevada. Muitos dos parâmetros estimados na matriz de relações contemporâneas apresentaram-se estatisticamente não significativos, fato que mostra a relevância de se utilizar uma modelagem dinâmica para analisar efeitos que ocorrem com defasagens.

No que diz respeito às relaçóes entre os mercados de soja e milho (complementaridade ou substitutibilidade), os resultados das funçóes de respostas a impulso demonstram que elas dependem do nível de mercado considerado. No caso de um choque no consumo aparente de milho ou no preço desse grão no segmento atacadista, prevalecem os efeitos de complementaridade. Assim, um aumento no consumo aparente de milho leva a um acréscimo no preço do milho e da soja e um aumento do preço do milho no atacado reduz o consumo do cereal, diminuindo também o consumo e o preço da soja. De outro lado, choques em variáveis relacionadas ao segmento produtor - preço de milho ou preço de soja - indicam substitutibilidade entre a leguminosa e o cereal. Por exemplo: um aumento do preço do milho leva a um aumento da oferta desse grão, reduzindo a oferta de soja e elevando o preço desta leguminosa.

Das variáveis macroeconômicas, a renda teve maior impacto na determinação do consumo aparente de milho (elasticidade acumulada $=0,34$ ) e a taxa de juros sobre os preços desse cereal, especialmente no atacado (elasticidade $=-0,23)$.

A demanda de milho responde, portanto, à variação do próprio preço quanto à variação do preço da soja. $\mathrm{O}$ efeito da renda ocorre com defasagens, sendo a relação contemporânea estimada para essa variável não significativa estatisticamente.

Os resultados apresentados possibilitam fazer inferências relevantes quanto ao processo de formação do preço do milho no Brasil. Em primeiro lugar, observa-se interação entre os mercados interno e externo de milho. Essa constatação aponta para a sensibilidade dos consumidores brasileiros de carnes (principalmente de aves e suínas) a choques no preço desse cereal no mercado internacional.

Os resultados indicam que, a despeito do crescimento da safra de milho de segundo semestre nos últimos anos, se considera que o efeito de substitutibi- 
lidade entre as atividades agrícolas relacionadas à produção do cereal e da leguminosa prevalece no período analisado. A estreita relação entre os mercados de soja - altamente desenvolvido - e de milho e também maior inserção do milho brasileiro no comércio internacional deve resultar em externalidades positivas.

Acredita-se que a principal contribuição deste trabalho foi a de analisar o efeito de determinantes da oferta e da demanda do milho sobre seu consumo e preço, relaçóes importantes para um segmento do agronegócio brasileiro, pouco estudado relativamente aos demais. Além disso, ele permitiu iniciar a compreensão das complexas relaçóes existentes entre a produção desse cereal e a sojicultura. 


\section{Referências bibliográficas}

\author{
ASSOCIAÇÃO BRASILEIRA \\ DAS INDÚSTRIAS DO \\ MILHO - ABIMILHO. \\ Estatísticas. Disponível em:< \\ http://www.abimilho.com.br/ \\ estatistica4.htm>. Acesso em: 7 \\ abr. 2009.
}

\section{BACCHI, M. R. P.}

Interdependência dos mercados de gasolina C e de álcool combustivel no Estado de São Paulo. 2007. 150p. Tese (Livre-Docência) Escola Superior de Agricultura

"Luiz de Queiroz", Universidade de São Paulo, Piracicaba, 2007.

BARROS, G. S. C. Economia da comercialização agrícola. Piracicaba: FEALQ, 1987.360p.

BARROS, G. S. C. Transmissão de preços pela Central de Abastecimento de Sáo Paulo. Revista Brasileira de Economia, v. 44, n. 1, p. 5-20, jan./mar. 1990.

\section{BASE DE DADOS DO} INSTUTO DE PESQUISAS ECONÔMICAS APLICADAS - IPEADATA. Dados

Macroeconômicos. Disponível em: <http://www.ipeadata.gov.br/ ipeaweb.dll/ipeadata?12236343>. Acesso em: 20 abr. 2009.

BRASIL. Ministério da Agricultura, Pecuária e Abastecimento. Cadeia produtiva do milho. Brasília: IICA/MAPA/ SPA, 2007.

\section{CHIODI, L. Integração}

espacial no mercado brasileiro de milho. 2006. 89p. Dissertação

(Mestrado em Economia

Aplicada) - Escola Superior de Agricultura "Luiz de Queiroz", Universidade de São Paulo,

Piracicaba, 2006.

COMPANHIA NACIONAL DE ABASTECIMENTO -

CONAB. Central de Informaçöes Agropecuárias. Disponível em: $<$ http://www.conab.gov.br/ conabweb/index.php?PAG=131>. Acesso em: 8 set. 2009.

ELLIOT, G.; ROTHENBERG, T. J.; STOCK, J. H. Efficient tests for an autoregressive unit root. Econometrica, Oxford, v. 64, n. 4, 1996.

Enders. W. Applied Econometric Time Series. 2. ed. New Jersey: John Wiley Sons, 2004. 480p.

HEIEN, D. M. Markup pricing in a dynamic model of the food industry. American Journal of Agricultural Economics, v. 61, n. 1, p. 10-18, Feb. 1980.

JOHANSEN, S. Statistical analysis of cointegration vectors. Journal of Economic Dynamics and
Control, Boston, v. 12, p. 23154, 1988.

\section{SISTEMA DO INSTITUTO} BRASILEIRO DE

GEOGRAFIA E ESTATÍSTICA DE RECUPERAÇÃO AUTOMÁTICA - SIDRA/ IBGE. Produção Agrícola Municipal. Disponível em: $<$ http://www.sidra.ibge.gov.br/ bda/acervo/acervo2>. Acesso em: 14 abr. 2009.

SOUZA, E. L. L.; AZEVEDO, P. F.; SAES, M. S. M. Competitividade do sistema agroindustrial do milho. In: FARINA, E. M. M. Q.; ZYLBERSZTAJN, D. Competitividade do agribusiness brasileiro. São Paulo: USP/ PENSA, 1998. p. 273-471.

VANDAELE, W. Applied Time Series and Box-Jenkins Models. Orlando: Flórida, Academic Press, Inc. (London) Ltda. 417p.

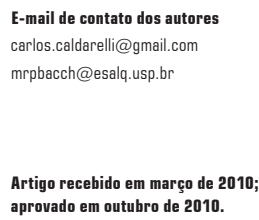

